Network Working Group

Request for Comments: 4691

Category: Informational
L. Andersson, Ed.

IAB

October 2006

\title{
Guidelines for Acting as an IETF Liaison to Another Organization
}

Status of This Memo

This memo provides information for the Internet community. It does not specify an Internet standard of any kind. Distribution of this memo is unlimited.

Copyright Notice

Copyright (C) The Internet Society (2006).

Abstract

Whenever the IETF decides to enter into a liaison relationship with another organization, such as a Standards Development Organization (SDO), a consortium, or an industrial forum, a liaison manager is appointed. The procedures used by the IAB to establish and maintain liaison relationships between the IETF and other organizations are described in RFC 4052. This document expands on the role of liaison managers and liaison representatives, giving guidelines on their mandate and the expectations, tasks, and responsibilities placed on them.

Table of Contents

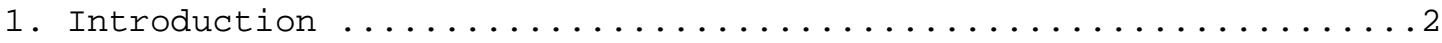

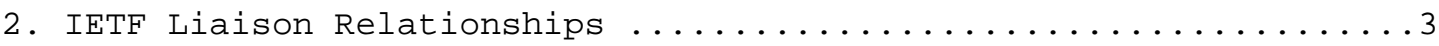

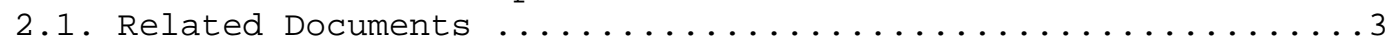

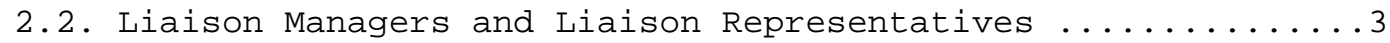

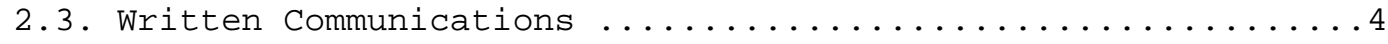

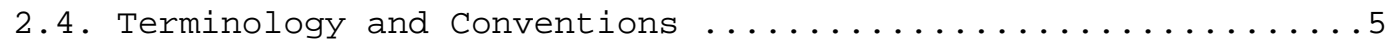

3. Guidelines for Liaison Managers and Representatives .........5

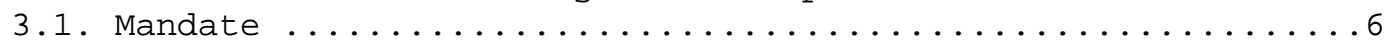

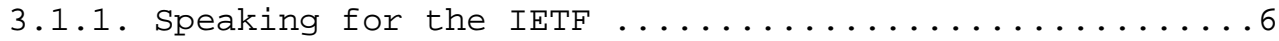

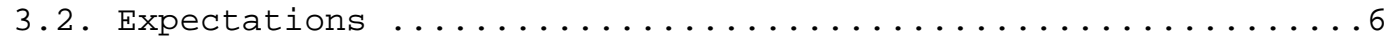

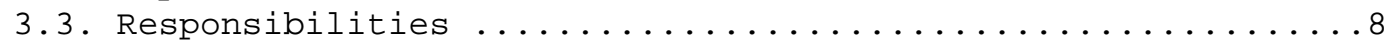

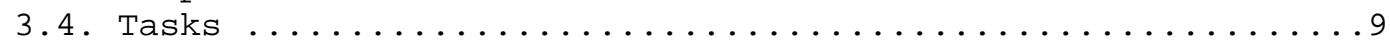

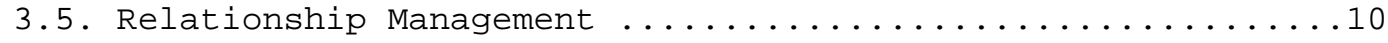

3.5.1. IETF Consensus Process on Liaison Statements ......10

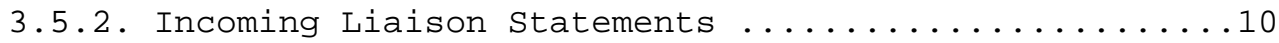

3.5.3. Ambiguous Incoming Liaison Statements ...........11

3.5.4. Liaison Managers Representing Peer Organizations ...11 


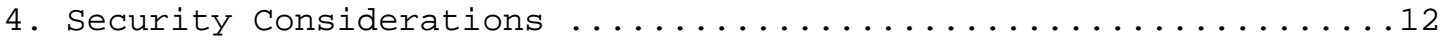

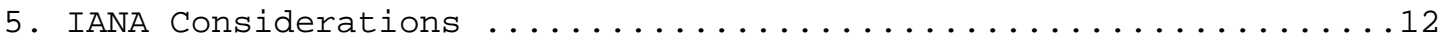

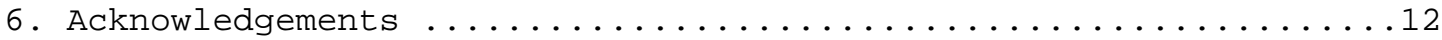

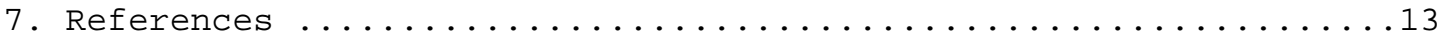

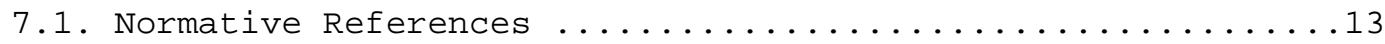

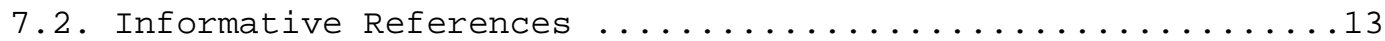

1. Introduction

In the course of developing Internet standards, the IETF needs to communicate extensively with various other peer organizations, including the following:

- Standards Development Organizations (SDOs) such as the Telecommunication Standardization Sector of the International Telecommunication Union (ITU-T) or standardization working groups of the Institute of Electrical and Electronics Engineers (e.g., IEEE 802)

- Consortia such as the World Wide Web Consortium (W3C)

- Industrial forums such as the Global Grid Forum (GGF)

These organizations are usually concerned with developing related standards and technical specifications, so that from time to time issues of coordination and mutual interest may arise. To facilitate communications, the IETF, through the Internet Architecture Board (IAB), establishes permanent liaison relationships with appropriate parts of these organizations according to the processes described in RFC 4052 [RFC4052].

Whenever the IETF decides to enter into a liaison relationship, a liaison manager and possibly some liaison representatives are appointed by the IAB to act as a channel between the IETF and the peer organization, typically in tandem with counterparts appointed by the peer organization.

Sections 2.2, 2.3, and 3 of RFC 4052 briefly set out the basic functions of the tasks of liaison managers and representatives. Over time, the number and importance of liaisons have grown, and the importance of the personal role of IETF liaison managers and representatives in maintaining effective relationships with peer organizations has grown concomitantly. This document supplements [RFC4052] by providing guidelines for liaison managers and liaison representatives in maintaining communications to peer organizations. 


\section{IETF Liaison Relationships}

A major goal of the IETF is to develop standards for the Internet, enabling the development of interoperable implementations. In order to develop Internet standards, it is frequently necessary for the IETF to communicate with other organizations that develop standards for other types of networks, for Internet applications, or for technologies that the Internet uses.

In some cases, the IETF and peer organizations consider it mutually beneficial to have a permanent formal relationship with certain rules governing the relationship. The organizations then enter into a "liaison relationship". At a high level, both sides agree to undertake certain responsibilities with respect to each other. The most basic liaison responsibility is to communicate information as necessary, and to respond to requests from peer organizations to which liaisons are maintained.

Decisions on IETF liaison relationships are the responsibility of the IAB. This includes whether or not the IETF should have a liaison relationship with a particular organization.

\subsection{Related Documents}

The IETF liaison process is specified in several documents. RFC 4052 [RFC4052] specifies how the IAB manages the IETF liaison relationship; RFC 4053 [RFC4053] specifies how liaison statements should be treated. Organization-specific agreements and documents may also be generated in some cases, e.g., RFC 3356 [RFC3356] describes the collaboration between the IETF and ITU-T, RFC 3113 [RFC3113] describes the relationship with the 3rd Generation Partnership Project (3GPP), and RFC 3131 [RFC3131] describes the one with the Third Generation Partnership Project 2 (3GPP2).

\subsection{Liaison Managers and Liaison Representatives}

Whenever the IETF enters into a liaison relationship with another organization, a liaison manager (often referred to as "the IETF liaison") is appointed by the IAB. This document expands on the mandate of and the expectations, tasks, and responsibilities placed on the liaison manager by section 2.2 of RFC 4052 .

In some cases, it may be necessary to have more than one person handling the liaison relationship with a given organization. For example, the time commitment required may be too substantial, or the technical scope of the liaison relationship may be too broad to be handled by a single individual. 
In such cases, the IAB may appoint one or more liaison representatives to supplement the work of the liaison manager by managing different aspects of the liaison relationship between the IETF and the other organization.

The value of personal relationships between the IETF liaison manager and representatives and members of the peer organization is central to the roles. The IAB will be looking for people who have both a good technical understanding of the work being carried out and effective personal relationships within the peer organization. Ongoing face-to-face interactions between the IETF liaisons and members of the peer organization are seen as critical to the effective functioning of the role. These interactions should allow the liaisons to keep the IETF abreast, and preferably ahead, of matters of mutual interest or potential conflict. When the liaison is working effectively, it should facilitate the IETF and the peer organization working synergistically and reduce the chance of overlapping or conflicting standards being created.

\subsection{Written Communications}

Aside from the personal contacts between liaisons and the peer organization, extensive communication may occur between the IETF and the peer organizations through written materials. Much of this communication is through liaison statements that typically contain plans, new developments, and time schedules of which one party believes that the other party should be aware.

The liaison manager should be aware of these written communications and assist both parties to see that appropriate action is taken in relation to liaison statements passing in both directions.

For example, when a liaison organization, such as ITU-T, needs to reference material that is under development in the IETF: the final reference in the peer organization's document needs the permanent identifier (RFC number) that will be assigned to the Internet Draft when it is approved and published. To meet the publication schedule of the peer organization, a liaison statement is often sent to the IETF requesting that an RFC number be assigned within the required timeframe. In response, the IETF can provide the RFC number or explain why it is not possible to provide this within the timeframe requested.

An alternative situation that involves more specific action by the liaison manager also involves requests for this kind of expedited action on RFCs. For example, 3GPP/3GPP2 and the Open Mobile Alliance (OMA) provide the IETF with an updated list of dependencies between their documents and IETF documents on a monthly basis, indicating 
what documents are needed and the required timeframe. In this case, the liaison manager tracks the dependency list and, when necessary, conveys the request for expedited assignment to the appropriate IETF Area Director (AD).

\subsection{Terminology and Conventions}

Terminology relating to IETF liaison procedures is found in [RFC4052]. Terms defined below are valid for this document only.

Liaison manager

A person appointed to manage an IETF liaison relationship with another organization.

Liaison representative

A person appointed to manage a certain (sub-) aspect of an IETF liaison relationship with another organization. Since it is only the scale of the responsibilities, mandate, and tasks that is different, the rest of this document only explicitly mentions liaison managers.

IETF consensus

RFC 2026 [RFC2026] and RFC 2418 [RFC2418] discuss the IETF consensus process. In this document, the term "IETF consensus" is used to indicate either consensus of the IETF as an organization, an area within IETF, or a working group. There the term "IETF consensus" needs to be interpreted in the context in which it is used.

The key words "MUST", "MUST NOT", "REQUIRED", "SHALL", "SHALL NOT", "SHOULD", "SHOULD NOT", "RECOMMENDED", "MAY", and "OPTIONAL" in this document are to be interpreted as described in RFC 2119 [RFC2119].

3. Guidelines for Liaison Managers and Representatives

Since liaison relationships are intended to be mutually beneficial, the IETF liaison to another organization must act as a bi-directional communication link between the IETF and the other organization. Since the liaison manager has been appointed by the IETF, the liaison manager needs to be responsive to the needs and aims of the IETF.

RFC 4052 lists some of the tasks and expectations relating to liaison managers and liaison representatives. This document expands on their mandate, provides more detailed discussion, and describes how the role is executed. 


\subsection{Mandate}

The mandate for IETF liaison managers is strictly limited to conveying IETF consensus to the liaised organization. The liaison manager MUST NOT on their own initiative send liaison statements to a liaised organization on behalf of IETF, or any of its areas and working groups. Liaison statements are only sent following the process specified in [RFC4052]. Liaison statements are only sent on the initiative of the IETF chair, the IAB chair, IETF Area Directors, or IETF working group chairs.

In Section 3.3 and section 3.4, responsibilities and tasks are listed that enable the IETF to obtain the information to correctly interact with the liaised organizations and to develop and clearly communicate IETF consensus.

\subsubsection{Speaking for the IETF}

The IETF functions based on rough consensus, which means that the right to speak for the IETF cannot be delegated. The liaison manager speaks on behalf of the IETF on the subject matter of the liaison, but only after making sure that the IETF consensus is understood. Some guidelines for understanding IETF consensus are provided above; however, the most important requirement is close and detailed coordination/consultation with the IETF community.

\subsection{Expectations}

There are certain expectations placed on liaison managers appointed by the IETF. Examples of these expectations are listed below.

Competences required

The key competence needed in the liaison manager or representative role is effective management of the liaison process according to the rules that have been agreed upon. The liaison acts as a representative of the IETF and not an independent voice with respect to topics of discussion in the liaison relationship. The liaison must therefore be careful to distinguish his or her own views from documented IETF consensus in dealings with the peer organization.

To this end, the liaison manager or representative must be able to communicate effectively with members of the peer organization, especially in face-to-face situations. This is important both to communicate the IETF's viewpoint and to gather information about the issues in the peer organization that the IETF needs to understand. 
In support of the liaison process, a person appointed to act as a liaison manager or representative on behalf of the IETF is expected to have a good technical understanding of the key issues in the subject area, as well as an understanding of the concerns important to stakeholders in both organizations.

An IETF liaison needs to have knowledge of the IETF's consensus process in general, as well as the consensus process(es) applying to the key issues within the liaison relationship.

The liaison must also have a good understanding of the processes used by the peer organization involved.

Perspective

Liaison relationships are designed for the mutual benefit of the organizations participating in the liaison. As such, swift information flow in both directions is a firm requirement. The role of an IETF liaison manager is to promote the interests of the IETF with respect to all topics within the scope of the liaison relationship. Since the liaison manager "wears an IETF hat", it is NOT the task of a liaison manager to promote the interests of the liaised organization within the IETF.

Distance

A liaison may not be able to maintain the required perspective if he or she is closely involved in the outcome of the work in the peer organization. A conflict of interest might arise if the liaison is involved in the management of the relevant part of the peer organization, has a close technical involvement in the work that is the subject of the liaison, or has a close interest in the outcome of the work in the peer organization through his or her employment. When appointing an appropriate person to manage a liaison relationship, the IAB needs to take into account any conflicts of interest that the individual being considered might have. Before a person is appointed to manage a liaison relationship, he or she will be asked to explicitly state any conflicts of interest. The IAB will not appoint a person to a liaison manager position if there is a strong conflict of interest. For example, an individual with an industry or organizational leadership position in an organization would typically not be suitable for appointment as an IETF liaison to that organization. 
Commitment and opportunity

A liaison manager needs to be committed to addressing the issues relevant to the liaison relationship. To handle the job properly, it is necessary that the liaison be able to allocate sufficient time to the task.

Timeliness

It is expected that a liaison manger will make the IETF aware of new developments in the subject area in a timely fashion.

\subsection{Responsibilities}

The liaison manager and representatives provide information to the IETF community in order to enable the IETF to make decisions based on the best possible information regarding the work in the peer organization. In turn, information communicated by the IETF liaison to the liaised organization MUST be based on the relevant IETF consensus. The liaison manager works with the liaised organization to ensure that communication is clear. As part of this, the liaison must clearly differentiate his or her own independent positions from those that represent IETF consensus.

It is the responsibility of the liaison manager to ensure that the liaised organization communicates its requirements to the IETF in a timely fashion and that the IETF consensus is clearly understood. This is particularly important in situations where the IETF and the liaised organization differ substantially in their positions. In this situation, the liaison manager needs to facilitate prompt communication so that the IETF and the liaised organization can stay in close communication and avoid misunderstandings.

The liaison manager and representatives are responsible for clearly and correctly communicating the IETF consensus position to the liaised organization. This includes, when specifically instructed, carrying any messages from the IETF to the peer organization. Generally, these communications "represent the IETF", and therefore due care and consensus must be applied in their construction.

The liaison manager and representatives are responsible for ensuring that relevant information originating from the liaised organization, or other information coming to the attention of the liaison, reaches the correct destination within the IETF, in a timely and effective way. 


\subsection{Tasks}

Examples of tasks performed by the liaison manager are provided below. Depending on the nature of the liaised organization, the task may vary in frequency and relative importance.

1. Attend relevant meetings and participate in conference calls and mailing lists within the liaised organization to gather information relevant to the liaison relationship. Note developments of interest for onward communication to the IETF. Communicate the point of view of the IETF consensus to the peer organization.

2. Communicate information relevant to the liaison relationship to the relevant part of the IETF either by written reports or verbally; this may involve briefings with a team of IETFers involved in the liaised organization and other interested parties within the IETF, e.g., working group chairs and ADs.

3. Understand the concerns of both the IETF and the peer organization, while ensuring that interests of the IETF are maintained; where there appear to be problems to solve or conflicts between approaches, work with both parties to encourage engineers from both organizations to collaborate on solving the problem and facilitate the development of engineering solutions in the appropriate organization.

4. Prepare reports giving updates on developments in the peer organization as requested by the IAB or other interested parties in the IETF. The target for these updates (e.g., the IAB, an AD, a WG) will typically be identified upon establishment of the liaison relationship and/or the appointment of the liaison manager.

5. Oversee delivery of liaison statements addressed to the IETF. This includes ensuring that liaison statements are delivered to the appropriate destination within the IETF, as well as shepherding the timely creation of responses by the IETF.

6. Work with the liaised organization to ensure that the IETF's liaison statements are appropriately directed and responded to in a timely fashion. To accomplish this, the liaison needs to build a contact network.

7. Communicate and coordinate with other IETF liaison managers where the activities of two or more liaised organizations overlap. 
8. Assist with the preparation of IETF liaison statements based on IETF consensus.

9. From time to time, liaison managers and liaison representatives will have to report to the IETF on the status of the liaison relationship. For this purpose, they will need to keep track of outstanding issues on behalf of the IETF. The frequency of the reports and the recipients of the reports within the IETF will be decided when the liaison relationship is set up and may be changed at any time by an IAB decision. IAB or other parties within the IETF may probe for liaison reports as needed or at regular intervals.

\subsection{Relationship Management}

Liaison managers will be involved in activities for which they are not directly responsible, but that might greatly benefit from their expertise. Some of these activities are outlined below.

\subsubsection{IETF Consensus Process on Liaison Statements}

Liaison statements and other messages sent to a liaised organization should be based on rough consensus within the IETF or one of its working groups or areas. Though the liaison manager is not responsible for determining consensus, it is important that the liaison manager participate in the process and makes his or her expertise and knowledge available.

How consensus is arrived at may vary according to the circumstances. Some issues are new, and in these cases an open discussion on a mailing list should be undertaken. For some issues, consensus has already been arrived at or the liaison statement is a mere statement of facts (e.g., to inform the liaised organization that an IETF Last Call had started on a document it had previously expressed interest in) and in these cases the liaison statement can be written and sent (such as by a working group chair), possibly involving the liaison manager.

\subsubsection{Incoming Liaison Statements}

When the IETF receives a liaison statement or other communication from an organization with which it has a liaison relationship that includes a request for a response to the communication, the IETF is committed to providing a timely response. This means that the IETF will respond within the time requested and provide information as accurately as possible. This commitment has been one of the key discussion points in the past, such as within the (g)mpls change process [GMPLS]. 
This commitment does not mean that the IETF will uncritically accept the content in the incoming liaison statement. To the extent that the liaison contains requirements on IETF technology or protocols, they will be taken into consideration based on their technical merit.

\subsubsection{Ambiguous Incoming Liaison Statements}

Sometimes the IETF, an IETF area, or an IETF working group receives liaison statements from a liaised organization that are sent to the wrong destination. At other times, the liaison statement is sent to working groups that are not chartered to do the work that the liaison statement addresses. In some cases, it might be the situation that no working group is chartered to do the work.

In such cases, the liaison manager should assist in finding the appropriate recipient within the IETF that might respond to the incoming liaison statement. Sometimes this might require that the intended response is made available for review on one of the IETF mailing lists.

\subsubsection{Liaison Managers Representing Peer Organizations}

Liaised organizations may appoint a person to act as a liaison manager for "their side" of the relationship. This is the person that will speak authoritatively, within the IETF, on the activities performed by the other organization. The other organization needs to make this person known to the IETF. This person might request a slot on a working group agenda to discuss developments and plans of the liaised organization.

Opinions expressed by a liaison mangers of other SDOs, other than reports on work within the liaised organization, are given equal weight with opinions expressed by other working group participants. RFC 3356 [RFC3356] describes this in the context of the relationship between the IETF and the ITU-T; however, the same model is applicable to all other organizations with which the IETF has a liaison relationship.

The mandates of liaison managers from other organizations are recognized by the IETF to the extent needed to understand the information received from the liaison manager. In all other respects he or she participates in IETF activities under the same conditions and rules as any other IETF participant. It is important that the IETF liaison manager understands the extent to which the peer liaison manager is mandated or delegated to speak on behalf of the peer organization, and to inform the relevant part of the IETF if the peer liaison manager appears to be stepping outside the role or stance given to him or her by the peer organization. 
IETF liaison managers should work to include the liaison manager from the liaised organization within their contact network, and to understand the positions being communicated by the peer liaison manager.

4. Security Considerations

This document does not specify any protocol or "bits on the wire". However, since interaction with other standards-making organizations often relates to security, the liaison manager can assist with security-related issues, resulting in improved security for Internet protocols.

5. IANA Considerations

There are no requests to the IANA herein. Note that the liaison manager very often has to understand and convey questions regarding IETF namespaces managed by IANA.

6. Acknowledgements

This document was developed as part of a conversation regarding the requirements on IETF liaison managers and representatives. Several IAB members have significantly contributed to the document. Also, the document has been improved thanks to suggestions and review from Allison Mankin, Dave Meyer, and Leslie Daigle.

A special thanks to Bernard Aboba, who, based on his experience as a liaison manager, has made many useful comments on the subject matter. Elwyn Davies and Bernard Aboba have both spent time correcting language and grammar.

Members of the IAB at the time of approval of this document were the following:

Bernard Aboba

Loa Andersion

Brian Carpenter

Leslie Daigle

Elwyn Davies

Kevin Fall

Olaf Kolkman

Kurtis Lindqvist

David Meyer

Dave Oran

Eric Rescorla

Dave Thaler

Lixia Zhang 
7. References

7.1. Normative References

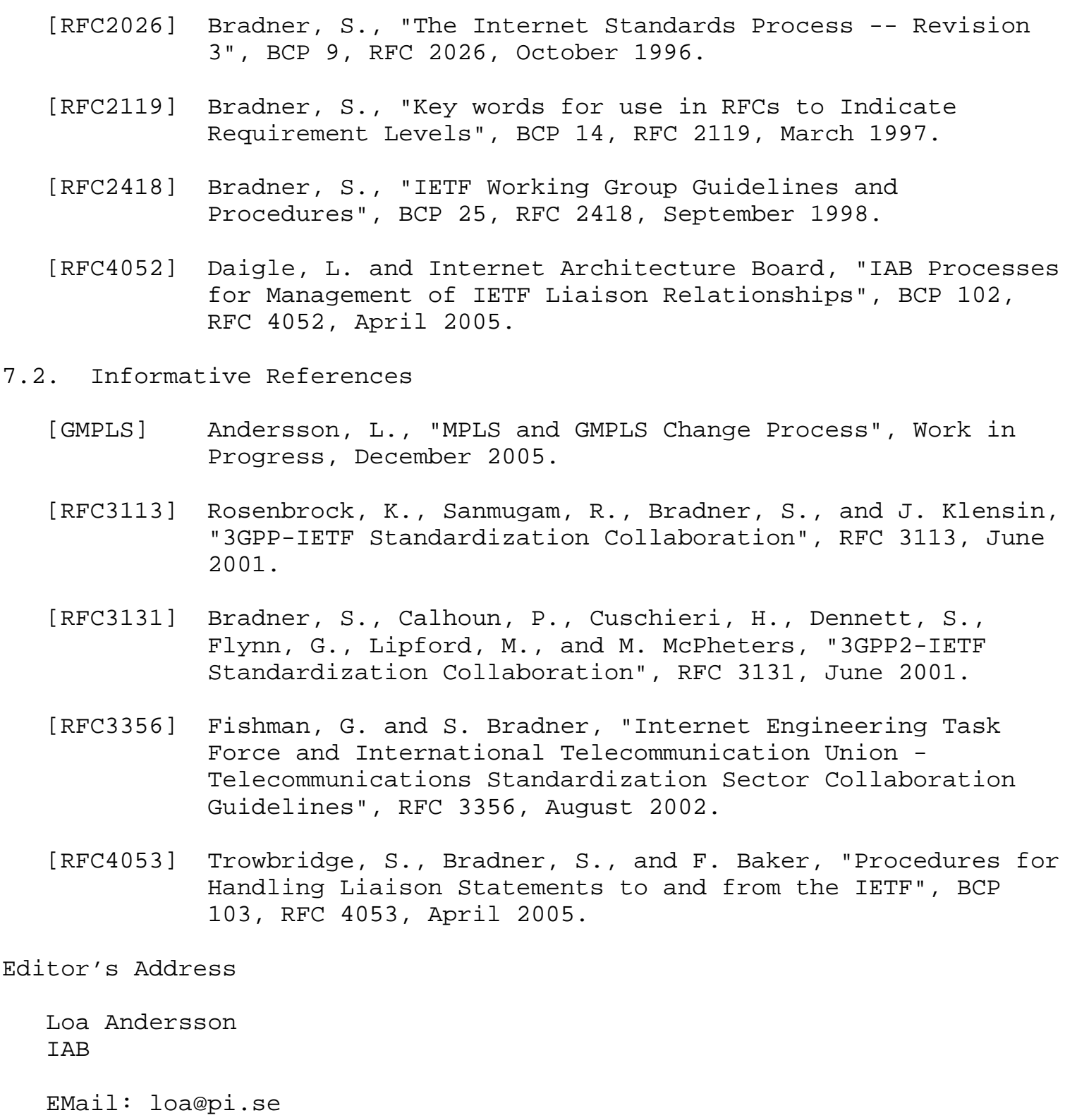


Full Copyright statement

Copyright (C) The Internet Society (2006).

This document is subject to the rights, licenses and restrictions contained in BCP 78, and except as set forth therein, the authors retain all their rights.

This document and the information contained herein are provided on an "AS IS" basis and THE CONTRIBUTOR, THE ORGANIZATION HE/SHE REPRESENTS OR IS SPONSORED BY (IF ANY), THE INTERNET SOCIETY AND THE INTERNET ENGINEERING TASK FORCE DISCLAIM ALL WARRANTIES, EXPRESS OR IMPLIED, INCLUDING BUT NOT LIMITED TO ANY WARRANTY THAT THE USE OF THE INFORMATION HEREIN WILL NOT INFRINGE ANY RIGHTS OR ANY IMPLIED WARRANTIES OF MERCHANTABILITY OR FITNESS FOR A PARTICULAR PURPOSE.

Intellectual Property

The IETF takes no position regarding the validity or scope of any Intellectual Property Rights or other rights that might be claimed to pertain to the implementation or use of the technology described in this document or the extent to which any license under such rights might or might not be available; nor does it represent that it has made any independent effort to identify any such rights. Information on the procedures with respect to rights in RFC documents can be found in BCP 78 and BCP 79 .

Copies of IPR disclosures made to the IETF Secretariat and any assurances of licenses to be made available, or the result of an attempt made to obtain a general license or permission for the use of such proprietary rights by implementers or users of this specification can be obtained from the IETF on-line IPR repository at http://www.ietf.org/ipr.

The IETF invites any interested party to bring to its attention any copyrights, patents or patent applications, or other proprietary rights that may cover technology that may be required to implement this standard. Please address the information to the IETF at ietf-ipreietf.org.

Acknowledgement

Funding for the RFC Editor function is provided by the IETF Administrative Support Activity (IASA). 